\title{
Mode of tele-communication and software used by children with hearing impairment.
}

\author{
Arjamand Zahra ${ }^{1}$, Sikander Ghayas Khan², Ayesha Kamal Butt ${ }^{2}$, Hafsa Noreen ${ }^{3 *}$, Muhammad Imtiaz \\ Saeed $^{4}$, Nayab Iftikhar ${ }^{2}$ \\ ${ }^{1}$ Department of Speech and Language Pathology, Speech and Language Therapist, Special Education Center, \\ Mamukanjan, Faisalabad, Pakistan \\ ${ }^{2}$ Riphah College of Rehabilitation Sciences, Riphah International University, Lahore, Pakistan \\ ${ }^{3}$ Department of Speech and Language Pathology, Riphah College of Rehabilitation Sciences, Riphah International \\ University, Lahore, Pakistan \\ ${ }^{4}$ Department of Linguistics, Applied Linguistics, Riphah International University, Lahore, Pakistan
}

\begin{abstract}
Objective: The study is being conducted to find out mode of tele-communication and software used by children with hearing impairment.

Methodology: This cross-sectional study was done at special education centers and schools in Lahore and Sheikhupura. Data was collected from children with hearing impairment by using a questionnaire of 11 items about the modes of tele-communication and software used by children with hearing impairment. Sample size was 362 which was calculated by using online sample size calculator. The population includes male and female children with mild, moderate, severe and profound hearing impairment studying in special education schools of Lahore and Sheikhupura. All these children use hearing aid and have congenital bilateral hearing loss.

Results: This study shows that almost $80 \%$ population of children with hearing impairment know about computer and mobile. They also have awareness about the use of computer, Facebook, e-mail etc. In addition, 40 to $50 \%$ children with hearing impairment use Skype, Facebook and e-mail as a communication tool.

Conclusion: The conclusion from this study is that most of the children use computer and mobile on daily basis in schools and homes for communication. Mild to moderate hearing loss children benefit from these devices between the ages of 10 to $20 \mathrm{y}$.
\end{abstract}

Keywords: Hearing impaired children (HIC), Tele-communication, Software, Digital devices.

Accepted on December 5, 2017

\section{Introduction}

Listening debilitation or listening misfortune happens when an individual get impaired smaller or the greater part of our capacity to listen. Different terms that are utilized to allude to listening weaknesses include terms such as hard of hearing or nearly deaf person with hearing impairment [1].

Hindrances to hearing are grouped according to the seriousness of the listening weakness and the kind of listening impairments. Mild hearing impairment patients have problems with sounds which have frequencies somewhere around 25 and $40 \mathrm{db}$. People at this level cannot hear delicate commotions and may experience difficulty taking after discussions in uproarious settings. Moderate hearing impairment patients have problems with sounds which have frequencies somewhere around 40 and $70 \mathrm{db}$. Severe hearing impairment patients have problems with sounds which have frequencies somewhere around 70 and $95 \mathrm{db}$. People at this level cannot hear most clamors and may depend on lip perusing and/or sign language even with the utilization of a listening aid. Profound hearing impairment patients have problems with sounds which have frequencies somewhere around $95 \mathrm{db}$ and over [2].

Hearing loss can be classified as conductive, sensorineural and mixed hearing loss. Conductive hearing loss involves the outer and middle ear, wax blockage, punctured eardrum, birth defects ear infection, or heredity, and often can be treated medically or surgically. Sensorineural hearing loss or deafness is related to the auditor nerve of hearing. Age, prenatal, postnatal, bacterial infections, heredity, trauma, exposure to loud noise, fluid and a benign tumor in the inner ear are the major causes of hearing loss. Loss in hearing ability is also observed due to problems related to inner ear damage. Mixed 
conductive and sensorineural hearing loss refers to a combination of injury and a problem that relates both to the external and inner ear $[3,4]$.

Different strategies are useful for communication with person having hearing impairment. Most commonly used method is total communication which is the combination of all methods which we are used by hearing impaired patients. However, pictures, signs, spoken language, FM [5]. System, Assistive Listening Devices (ALDs) and Augmentative and Alternative Communication (AAC) help people with communication disorders to express themselves. These devices range from a simple picture board to a computer program that synthesizes speech from text. Alternating devices are connected to doorbells, telephones, or alarms that emit loud sounds or blinking lights to let someone with hearing loss know that an event is taking place [6].

Social networks has been used by many persons with disabilities and among them common users are hearing impaired. It has been proved in an online survey that Facebook is the most favourite and used app among hearing impaired students. Results show that they use Facebook to be in contact with other hearing impaired friends and with those friends who has no disability [7].

All new cordless phones are DECT (Digital Enhanced Cordless Telecommunications) and have better sound quality than analogue cordless phones. ABT Tone Caller makes it easier when phone is ringing, with an extra sound alert to let you know that you have received a call. Text messaging or Short Message Service (SMS] is a quick, cheap and easy way to keep in touch and is very useful if you have a hearing loss or speech impairment [8].

$\mathrm{ViBe}$ is a communication Android app that allows users to set vibration patterns for contacts. It is also designed as an accessibility tool for disabled individuals, most notably for the blinds and hearing impaired ones. Camfrog (a video chat client that was created by Camshare LLC). was first launched in 2003. It allows users to send instant messages to each other privately. Users can also interact via a private one-on-one audio/video chat. Unlike most instant messaging programs, users can also connect to chat rooms to view other users' text, audio, or video chat. Skype is another software application that allows voice and text communication over the internet and allows free calls to other users within the Skype services. Sky has become popular for its traditional features, which include instant messaging, file transfer, and video conferencing [9].

There are many products and technologies which help deaf persons at schools and homes for socializing with friends [10]. Hearing impaired people are employed in every occupational field, so most HI people tend to have special electronics and telecommunications equipment at homes. One technique which is employed utilizes a teletype machine by HIC person to transmit and receive messages and can also communicate easily because of the effective connection directly between them. This teletype machine effectively understands written information received from HIC people [11]. Hearing impaired persons are well schooled in sign language to express themselves with facial expression and body motion. A written message received by a teletype machine or computer may not convey any emotional content that are present in voice of person [12-14].

Internet provides an alternative way for social environment. The process of communication among hearing impaired children is also improving rapidly due to the use of internet. Software that makes use of voice and video channels have become more common these days [15].

Hearing impaired persons are motivated to use the internet especially for interpersonal contacts with persons having no hearing loss. Deaf people have initiated a range of specialist websites which provide information aimed at fulfilling their communication needs and providing them opportunities to connect with other deaf people. Deaf people are active users of the internet due to which new telecommunication modes and software are specially designed for the deaf [16]. Hearingimpaired persons are motivated to use the internet more than their hearing counterparts. This use of internet by the hearingimpaired people is characterized by lengthier time spent on the internet and more solitary activities. Hearing-impaired persons are although using internet software (e.g., search engines) in similar fashion to their hearing counterparts such as both of them uses personal and group-communication tools $[10,17]$.

\section{Methodology}

This cross sectional study was done at special education centers and schools for children with hearing impairment in Lahore and Sheikhupura. Study was completed within 6 months (July 2016 to Dec 2016). Convenient sampling technique was used for the purpose of data collection. Sample size was calculated 362 , by using online sample size calculator. Inclusion criteria includes those children with hearing impairment who had normal IQ and with moderate to severe hearing loss and they were able to communicate face to face by using sign language. The age of participants was 10 to $20 \mathrm{y}$. All children with hearing impairment who had any co morbid conditions were excluded from the study (congenital and chronic systematic diseases). Questionnaire was comprised of 11 items about the tele-communication modes and software used by children with hearing impairment. The first part of the questionnaire consisted of demographic information (e.g. gender, age, qualification severity level, etc.) and the second part of the questionnaire consisted of 11 statements. These statements were related to the mode of tele-communication and software used by children with hearing impairment. The four options were given to reply included never, sometime, always and don't know in front of each statement. The content of questionnaire was validated through literature and Lynn method. Different Special education centers and schools for the children with hearing impairment were visited to collect the data after taking the permission of the principal and informed consent of the participant. The results were extracted by using SPSS 16, conclusions were drawn, suggestions and recommendations were also made. 
Mode of tele-communication and software used by children with hearing impairment

\section{Results}

Table 1. Frequency distribution of children with Hearing Impairment on the basis of gender.

\begin{tabular}{lll}
\hline Gender & Frequency & Percentage \\
\hline Male & 144 & 39.8 \\
\hline Female & 218 & 60.2 \\
\hline Total & 362 & 100 \\
\hline
\end{tabular}

Table 2. Class wise frequency and percentage of children with hearing impairment.

\begin{tabular}{lll}
\hline Class & Frequency & Percentage \\
\hline $5^{\text {th }}$ to $6^{\text {th }}$ & 101 & 27.9 \\
\hline
\end{tabular}

\begin{tabular}{lll}
\hline $7^{\text {th }}$ to $8^{\text {th }}$ & 159 & 43.9 \\
\hline $9^{\text {th }}$ to $10^{\text {th }}$ & 102 & 28.2 \\
\hline Total & 362 & 100 \\
\hline
\end{tabular}

Table 3. Frequency distribution of children with hearing impairment on the basis of age.

\begin{tabular}{lll}
\hline Age & Frequency & Percentage \\
\hline 10 to 12 & 135 & 37.3 \\
\hline 13 to 15 & 138 & 38.1 \\
\hline 16 to 18 & 89 & 24.6 \\
\hline Total & 362 & 100 \\
\hline
\end{tabular}

Table 4. Use of the software and tele-communication modes.

\begin{tabular}{|c|c|c|c|c|c|}
\hline Statements & Symbols & Never & Always & Sometime & Don't know \\
\hline 1. I use computer or laptop for communication & & $9.10 \%$ & $38.80 \%$ & $51.10 \%$ & $1 \%$ \\
\hline 2. I use mobile messages for communication & & $0.60 \%$ & $78.60 \%$ & $19.90 \%$ & $1 \%$ \\
\hline 3. I use IMO software for communication & & $71.70 \%$ & $1 \%$ & $0.30 \%$ & $27.10 \%$ \\
\hline 4. I use Facebook for communication & & $29.30 \%$ & $1.90 \%$ & $68.50 \%$ & $0.30 \%$ \\
\hline 5.I use Face E-mail for communication & & $3.60 \%$ & $49.40 \%$ & $46.70 \%$ & $0.30 \%$ \\
\hline 6. I use Whatsapp software for communication & & $56.90 \%$ & $4.70 \%$ & $37.80 \%$ & $0.60 \%$ \\
\hline 7. I use Viber software for communication & & $53.00 \%$ & $0.80 \%$ & $45.90 \%$ & $0.30 \%$ \\
\hline 8. I use Skype software for communication & & $19.60 \%$ & $24.90 \%$ & $50.80 \%$ & $4.70 \%$ \\
\hline 9. I use Line software for communication & & $78.50 \%$ & $1.40 \%$ & $14.40 \%$ & $5.80 \%$ \\
\hline 10.I use Twitter software for communication & & $56.90 \%$ & $1.70 \%$ & $34.80 \%$ & $6.60 \%$ \\
\hline 11. I use Camfrog software for communication & & $20.30 \%$ & $1 \%$ & $1 \%$ & $77.70 \%$ \\
\hline
\end{tabular}

This study shows that almost $80 \%$ population of children with hearing impairment knows about computer and mobile. They also have awareness about the use of computer, mobile, face book, e-mail etc. In addition, 40 to $50 \%$ children with hearing impairment use Skype, Facebook and e-mail as a communication tool (Tables 1-4).

\section{Discussion}

This study shows that majority of the hearing impaired children $(80 \%$ population of children with hearing impairment). know about computer and mobile. Most of them have awareness about the use of computer, mobile, Facebook, e-mail etc. In addition, reasonable number of these children (40 to $50 \%$ ). Use Skype, Facebook and e-mailing as a 
communication tool [18]. As for as the use of Twitter is concerned almost $56.9 \%$ children never used it $1 \%$ always and $34 \%$ used it sometimes. In this connection, $78.5 \%$ children never used Line software for communication, $1.4 \%$ always used it and 14.4\% sometimes used it. SMS and Emails are found to be the most common and frequent modes used by the children for communication purposes. On the other hand, Camfrog is found to be the least known software in this research. In addition, $37.8 \%$ children with hearing impairment sometimes used Whatsapp for communication, $4.7 \%$ children with hearing impairment always use Whatsapp software as a communication tool, $45.9 \%$ children with hearing impairment sometime used Viber software for communication, $53.0 \%$ children with hearing impairment never used Viber software for communication, $50.8 \%$ children with hearing impairment sometimes used Skype software for communication and $24.9 \%$ children with hearing impairment always used Skype for communication.

Comparison with other researches in this area also shows that SMS is the most frequent method used by the hearing impaired children. This study shows that $72.7 \%$ children with hearing impairment never used IMO software for communication. $27.1 \%$ children with hearing impairment do not know about IMO software and have never used it. Whereas in 2004, the UWC BANG conducted a research on children having agegroup between the age of 15 to 24 in which $20 \%$ deaf children used IMO software for communication. As for as the use of Facebook for communicative purposes is concerned, this research shows that $68.5 \%$ children with hearing impairment used Facebook for communication sometimes while 7\% always used Facebook as a communication tool. However, the UWC BANG research conducted in 2004, on children having age-group between the age of 15 to 24 , shows that $50 \%$ deaf used Facebook in this regard [18]. In addition, 49.4\% children with hearing impairment always used e-mail for communication, $46.7 \%$ children with hearing impairment used e-mail sometimes whereas in UWC BANG research 70\% deaf used e-mail for communication. In relation to the use of computers, $51.1 \%$ children with hearing impairment, in this research, used computer sometimes for communication whereas in UWC BANG's research 39.8\% children with hearing impairment always used computer for communication. Moreover, $79.6 \%$ children with hearing impairment always used mobiles for communication in this research and in UWC BANG's research, $19.9 \%$ children with hearing impairment use mobiles sometimes as a communication tool.

The Universal Service Agency (USA) conducted a survey in 1996 , in which out of a sample of 47 children with hearing impairment only $23 \%$ actually used mobile for communication [19]. In August, 2012 University of the Western Cape, South Africa conducted a survey in which $81.25 \%$ deaf participant used mobile phone for SMS and video-messaging service. According to results only $14 \%$ of teachers in deaf schools can communicate through mobile with deaf for communication [20].
In 2009, the Australian Association of the Deaf, surveyed people who identify themselves as deaf by mail. Results showed that Short Message Service (SMS), telephone typewriters (TTY), voice/TTY relay services, fax, and e-mail were used regularly. Deaf users are discerning of the purposes for which they use each method for instance: SMS for social and personal interactions, TTY for longer communications and (via the relay service). with people and services without TTYs, fax for business and social contact, and computers for personal and business e-mails as well as Web browsing, accessing chat rooms, word processing, games, and study. Literature has supported that deaf community used social apps usually and its use is common among them [21].

A deaf communications technology study done by Wang at the DCCT indicated that even though $90 \%$ deaf people in the DCCT used SMS to communicate, they were very concerned about the cost of using the technology. This study indicated that they used other text messaging communication tools to communicate as well: $40 \%$ used Mxit, 26\% used e-mail, and $28 \%$ had a Facebook account. Wang further indicated that $87 \%$ of deaf mobile phone users would be interested in using video communication systems for mobile phones and over $58 \%$ of them indicated that they would like to try using mobile video communication applications if they are free and this study correlates with our results [5].

A study done by Pilling and Barret in 2007 indicated that, in general, deaf people used several forms of text communication, but they selected each for a specific purpose, e.g. SMS for communication with family and friends, and e-mail for communication and sending files. In the United Kingdom, email and SMS were the most widely used forms of text communication among deaf users, but SMS was mostly used by younger deaf users [22].

In an Australian study, several trials of different communication methods were conducted with deaf (hard of hearing or deaf) participants who mainly used sign language to communicate and it was found that SMS became the most frequently used means of communication when people were given a mobile phone that they had not used before [3].

\section{References}

1. Shemesh R. Hearing impairment: definitions, assessment and management. Int Encycloped Rehab 2010.

2. Darai B. Using sound field FM systems to improve literacy scores. Adv Speech Lang Patholog Audiolog ALD Appl 2000; 10: 5 .

3. Boulares M, Jemni M, editors. Mobile sign language translation system for deaf community. Proc Int Cross Discipl Conference Web Access 2012.

4. Shemesh R. Hearing impairment: definitions, assessment and management. clinical audiologist department of communication disorders. Faculty of Social Welfare \& Health Sciences. University of Haifa; 2010

5. Chininthorn P, Glaser M, Freudenthal A, Tucker WD. Mobile communication tools for a South African Deaf 
patient in a pharmacy context. IIMC Int Info Manag Corp 2012.

6. Doughty K. SPAs (smart phone applications)-a new form of assistive technology. J Assist Technol 2011; 5: 88-94.

7. Shpigelman CN, Gill CJ. Facebook use by persons with disabilities. J Comp Med Commun 2014; 19: 610-624.

8. Taylor JL, Dove D, Veenstra-VanderWeele J, Sathe NA, McPheeters ML, Jerome RN. Excluded Studies. Pediatrics 2012.

9. Liebermann R. Telephone for the deaf and method of using same. Google Patents 1999.

10. Stelmachowicz PG, Pittman AL, Hoover BM, Lewis DE. Effect of stimulus bandwidth on the perception of $/ \mathrm{s} / \mathrm{in}$ normal-and hearing-impaired children and adults. J Acous Soc Am 2001; 110: 2183-2190.

11. Hasselbring TS, Glaser CHW. Use of computer technology to help students with special needs. Future Children 2000; 102-122.

12. Watkin P, McCann D, Law C. Language ability in children with permanent hearing impairment: the influence of early management and family participation. Pediatrics 2007; 120 : 694-701.

13. Scherer MJ. Outcomes of assistive technology use on quality of life. Disab Rehab 1996; 18: 439-448.

14. Chinn KM, Moulton RD, Gentry MM. Effectiveness of multimedia reading materials when used with children who are deaf. Am Ann Deaf 2005; 149: 394-403.

15. Mary R. Power Dp deaf people communicating via SMS, TTY, relay service, fax and comupter in Australia. J Deaf Studies Deaf Educ 2007; 12: 1973.

16. Vaccari C, Marschark M. Communication between parents and deaf children: implications for social-emotional development. J Child Psychol Psych 1997; 38: 793-801.
17. Barak A, Sadovsky Y. Internet use and personal empowerment of hearing-impaired adolescents. Comp Human Behav 2008; 24: 1802-1815.

18. Glaser M, Tucker WD. Telecommunications bridging between Deaf and hearing users in South Africa. Univ West Cape 2004.

19. Wake M, Poulakis Z, Hughes E, Carey-Sargeant C, Rickards F. Hearing impairment: a population study of age at diagnosis, severity, and language outcomes at 7-8 years. Arc Dis Childhood 2005; 90: 238-244.

20. Mutemwa M, Tucker WD. A mobile Deaf-to-hearing communication aid for medical diagnosis. Univ West Cape 2010.

21. Power MR, Power D, Horstmanshof L. Deaf people communicating via SMS, TTY, relay service, fax, and computers in Australia. J Deaf Studies Deaf Educ 2007; 12: 80-92.

22. Pilling D, Barrett P, Floyd M. Disabled people and the internet: experiences, barriers and opportunities. City Res Online 2004.

\section{*Correspondence to}

Hafsa Noreen

Department of Speech and Language Patholgy

Riphah College of Rehabilitation Sciences

Riphah International University

Pakistan 